\title{
A boca da mulher no poema Psiu de Augusto de Campos
}

Monalisa Medrado BOMFIM, Universidade Federal de São Carlos.

A poesia concreta possui um período de considerável militância política que podemos identificar como: fase participante (1960-1966). Nesse trabalho, enfocaremos a análise de Psiu (1966), poema-cartaz de Augusto de Campos que chama a atenção por possuir forte tom político, o qual nos propomos a interpretar pelo viés das lutas feministas. Esse recorte é sugerido pelo próprio poema, que apresenta, no centro do círculo que o constitui, uma boca feminina sensual que pede silêncio. Na nossa leitura, esse silêncio pode ser relacionado com a repressão do regime ditatorial brasileiro, mas também pode ser o silenciamento das lutas feministas durante a ditadura ou ainda o silenciamento histórico imposto às mulheres como classe social.

PALAVRAS-CHAVE: poesia concreta; silenciamento; corpo das mulheres; liberdade; feminismo. 
Beduíno, você quer saber se eu sou livre? O que quero com a minha liberdade? ${ }^{2}$ Julio Bressane In: Beduíno

O paulistano Augusto de Campos (1931) iniciou em 1952, junto com seu irmão Haroldo de Campos e amigo Décio Pignatari, a poesia concreta brasileira, importante movimento de vanguarda nacional que se expressou em diferentes campos artísticos, como a poesia, a pintura, a escultura e o design. Para os irmãos Campos e Décio Pignatari essa experiência começa com a publicação da revista Noigandres (1952-1962), que era constituída por poemas concretos e textos em tom de manifestos, o principal deles é o manifesto: Plano-piloto para poesia concreta, escrito pelo trio e publicado em 1958, na Noigandres $\mathrm{n}^{\mathrm{O}} 4$, pois elucida, em um texto sintético e carregado de referências, bem aos moldes concretistas, as principais caraterísticas do poema concreto. Essa primeira fase (19561960), na qual a poesia concreta define e articula elementos tão seus como: o paideuma a a "valorização expressionista do espaço" (CAMPOS, PIGNATARI e CAMPOS, 1975, p. 156) e a experimentação verbivocovisual 3 , pode ser denominada como fase ortodoxa, pois busca justamente legitimar o concretismo como movimento artístico individual e com produções próprias.

A fase ortodoxa do concretismo acontece em um período histórico favorável para o desenvolvimento de ideias inovadoras, marcado sobretudo pela presidência de Juscelino Kubitschek, que prometia uma ascensão econômica quase milagrosa e foi responsável pela construção de Brasília, cujo planejamento e arquitetura refletem a ideia de progresso que acompanhava o governo de JK. Existe consonância evidente entre o desejo de desenvolvimento defendido pelo governo JK e de inovação dos poetas concretos, de modo que o projeto de Brasília aparece no título do

\footnotetext{
${ }^{1}$ Frases enunciadas pela personagem Surma, interpretada por Alessandra Negrini, no filme Beduíno (2016), dirigido e roteirizado por Julio Bressane.

${ }^{2}$ Paideuma é um conceito que Ezra Pound desenvolve no livro ABC da literatura (1934). Os concretistas entendiam o paideuma como o "elenco de autores culturmorfologicamente atuantes no momento histórico = evolução qualitativa da expressão poética e suas táticas” (CAMPOS, 1975, p. 47). Entre os escritores que faziam parte do paideuma concretista, podemos citar, além do próprio Ezra Pound, James Joyce, Mallarmé, cummings, Oswald de Andrade e João Cabral de Melo Neto.

3 Verbivocovisual é um conceito de James Joyce, que considera a contribuição dos elementos de forma, tipográfico-visuais e sonoros, na composição e significação do poema. No manifesto Plano-Piloto para Poesia Concreta (CAMPOS, PIGNATARI e CAMPOS, 1975, p. 157), verbivocovisual é aquela característica "que participa das vantagens da comunicação não-verbal, sem abdicar das virtualidades da palavra".
} 
manifesto Plano-piloto para poesia concreta (1975). O golpe militar de 1964 muda radicalmente esse cenário, a repressão e a fragmentação do estado democrático, acompanhados dos decretos dos atos institucionais, suspendiam direitos políticos e silenciavam dia a dia a expressão artística e os movimentos de classe nacionais. Nesse contexto, a poesia concreta assume um caráter questionador e crítico, caracterizando a fase participante ou militante que, de acordo o crítico de Gonzalo Aguilar (2005), vai de 1960 a 1966.

Augusto de Campos produziu na fase participante poemas que fazem críticas ácidas ao governo ditatorial e que continuam sendo experimentais. Alguns desses trabalhos foram expostos em dezembro de 1964 na Galeria Atrium, na série denominada Popcretos (1964-1966). Ricos em colagens ao estilo do cubismo e do ready-made, os poemas da série Popcretos realizavam uma leitura crítica e antropofágica do contexto brasileiro do golpe militar, entre as produções de Augusto de Campos mais debatidas dessa série podemos citar: Greve (1964), olho por olho (1964) e Psiu (1966).

A forma como se organizam os materiais do arquivo difere dos modos como o concretismo dos anos 1950 o fazia. Mediante a inclusão do pop e do aleatório, o trabalho com a experiência já não está em função da ruptura modernista, e sim da aglomeração, da sobreposição e da intermediação do mass media. O poema "Psiu", composto em 1966, dois anos depois da exposição, processa este novo repertório virtualmente infinito (as palavras dos jornais) com a comoção política: o golpe militar de 1964 e as novas condições repressivas que impôs ("ato 13 ” no poema) explicam e permitem ler o poema. (AGUILAR, 2005, p. 110).

Psiu (1966) é um poema-cartaz que foi incluído posteriormente à série Popcretos, portanto, não participa da exposição realizada na Galeria Atrium. Augusto de Campos escolhe mantê-lo na seleção dos poemas Popcretos devido sua alta carga política, que, conforme observa Aguilar (2005), está por exemplo no "Ato 13" colocado em destaque no poema, que remete ao ato institucional número três (AI-3), decretado em fevereiro de 1966, pelo presidente Humberto de Alencar Castelo Branco. $\mathrm{O}$ AI-3 regularizava as eleições indiretas nacionais para governador e, consequentemente, auxiliava no cenário de diluição da democracia no autoritarismo militar do golpe. Pesquisas realizadas por Thiago Moreira Correa (2012) e Daniel Rangel Costa (2019) chamam a atenção para outros intertextos relacionados com o contexto políticoeconômico do 
golpe de 1964 que são relevantes em Psiu (1966). Correa (2012, p. 59), por exemplo, separa, no poema, as temáticas políticas das econômicas e observa que, no "Ato 13", "o ponto de interrogação dentro da letra 'o' da palavra 'ato' questiona esse recurso político da época”. A análise de Costa (2019), por sua vez, traz ainda uma outra informação sobre o "Ato 13", cujo número 13 representaria, segundo o próprio Augusto de Campos, uma alegoria da "infelicidade da situação brasileira dessa época" (COSTA, 2019, p. 72).

A temática política que prevalece nas análises tanto de Correa (2012) como de Costa (2019) é o do silenciamento promovidos pela censura ditatorial, em ambas as análises ela está associada sobretudo à figura hexagonal central: a boca. De acordo com Correa (2012), a boca de Psiu (1966) pode representar: estupefação ou reflexão; seja como for, os dois gestos se realizam na forma do silêncio ou no gesto de pedir silêncio, que segundo o pesquisador soa irônico, por conta da censura. Para Costa (2019), a imagem da boca quase fechada pode "representar o silêncio imposto pelo regime ou da voz do poema que tenta declamar". Posto que a imagem da boca tem sido associada à expressão do silêncio nas pesquisas da área, e que esse silêncio se infiltra na interpretação das palavras que constituem o perímetro do poema, é relevante observar ainda que a boca de Psiu (1966) é uma boca de mulher.

Psiu (1966) é um poema-circulo, no centro uma boca de mulher, que o crítico David Jackson (2004, p. 17) considera até mesmo como um “emblema de paixão". Isso porque, para Jackson (2004, p. 18), quando encaramos Psiu (1966) nosso "olho passa do mundo da propaganda do sexo e do jornalismo e TV baratos para o elementos de uma leitura crítica”, assim "o leitor é chamado pelo irresistível 'psiu!' e olha pelo buraco para ser 'deglutido' pelo círculo televisivo e pela boca fatal”. Na nossa leitura, a boca sensual de femme fatale converte-se em um fetiche pelo corpo da mulher, que perpassa a objetificação e o silenciamento desse corpo, temáticas recorrentes nas pautas da luta feminista. Nessa hipótese, a boca central infiltra-se no texto que compõe o círculo, ampliando o horizonte interpretativo do poema, cuja forma geométrica circular contem em si um horizonte infinito, dado pela infinidade do perímetro em continuidade, pois não apresenta arestas. Assim, propem-se trabalho uma análise crítica do poema Psiu (1966) pela perspectiva das lutas femininas que podem ser recortadas do poema. 


\section{Figura 1. Poema Psiu (1966), de Augusto de Campos, compõe a série dos poemas popcretos (1964-1965).}

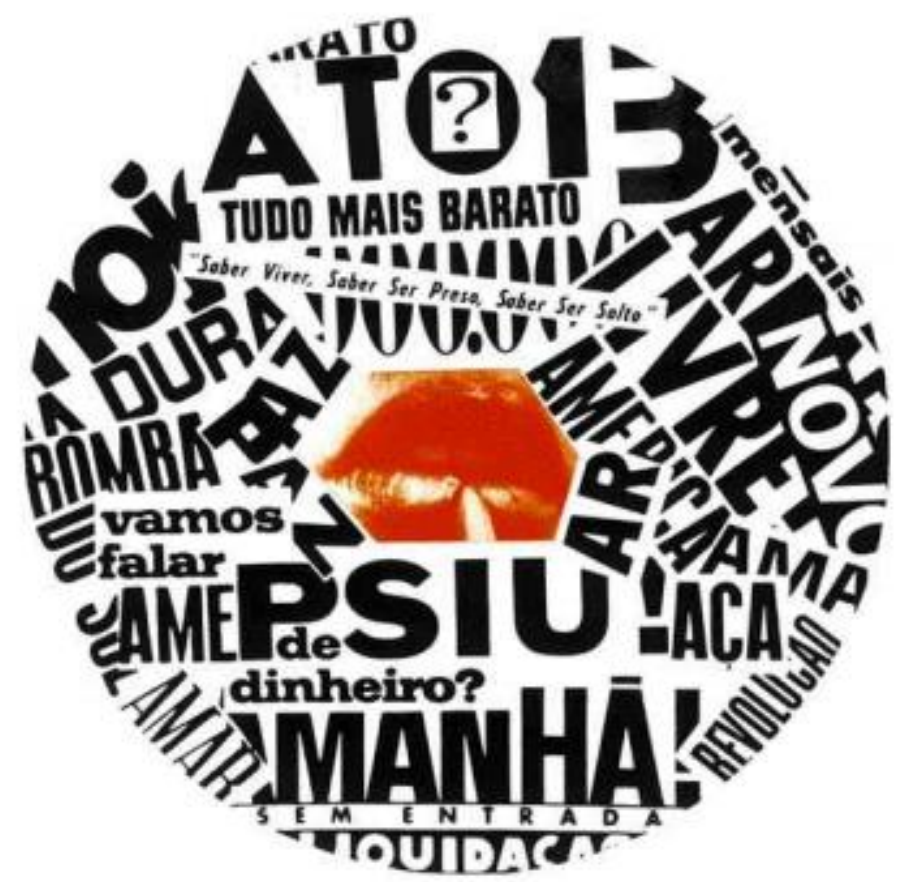

Fonte: Poema disponível no link:

$<\mathrm{http}$ ://www.augustodecampos.com.br/popcretos.html >.

A poesia concreta permite o movimento de presentificação do poema 4 , dado o caráter sincrônico dessa poesia interpreta-la a luz de diferentes teorias e lutas. Psiu (1966), como um poema da fase participativa da poesia concreta, também permite esse tipo de manobra. Além disso, a análise de Psiu (1966) pelo viés da luta feminista reitera o caráter político e crítico do poema.

O feminismo, como movimento social, é um movimento essencialmente moderno, surge no contexto das ideias iluministas e das ideias transformadoras da Revolução Francesa e da Americana e se espalha, em um primeiro momento, em torno da demanda por direitos sociais e políticos. Nesse seu alvorecer, mobilizou mulheres de muitos países da Europa, dos Estados Unidos e, posteriormente, de alguns países da América Latina, tendo seu auge na luta sufragista. Ao utilizar essa bandeira de luta, o movimento feminista chama a atenção das mulheres sobre o caráter político da sua opressão, vivenciada de forma isolada e individualizada no mundo do privado, identificada como meramente pessoal. (COSTA, 2009, p. 52-53).

4 Haroldo de Campos, no manifesto olho por olho a olho nu (1975, p. 46), escreve sobre a poesia concreta: "uma arte - não q apresente - mas q presentifique o OBJETO" (grafia e caixa alta obedecem a estética do texto do autor). 
A pesquisadora Ana Alice Alcântara Costa (2009) aponta que, no Brasil, os primeiros movimentos feministas datam de 1832 e foram liderados por Nísia Floresta (1810-1885), primeira educadora feminista brasileira. Desde então as lutas feministas nacionais foram responsáveis por conquistas fundamentais para as mulheres, como o direito ao voto em 1932. Entretanto, Costa (2009) observa que após o golpe militar de 1964, essas lutas sofreram fortes silenciamentos oriundos da repressão aplicada pelo Estado ditatorial. Esse silêncio, que perdura historicamente até 1968, está na boca feminina de Psiu (1966), como se o corpo da mulher fosse reduzido a boca, enquanto a boca figura a mudez. Assim, Psiu (1966) pode ser interpretado como um poema político, que também faz referência as lutas feministas silenciadas no contexto da ditadura brasileira. No poema, a figuração do silêncio pode representar, portanto, o silenciamento que é imposto às mulheres e aos seus corpos. Segundo Michelle Perrot (2003, p. 15-16), isso acontece porque "o silêncio envolve também a vida íntima do corpo da mulher. [...] A vida sexual, cuidadosamente diferenciada da procriação, também permanece oculta. O prazer feminino é negado, até mesmo reprovado: coisa de prostituta”.

Em Psiu (1966) o fato da boca ser sensual, traz para a perspectiva da interpretação o erotismo da mulher. No discurso literário, uma das primeiras mulheres que escreve sobre a temática do silenciamento desse erotismo é Simone Beauvoir. No livro O segundo sexo, Beauvoir (1980, p. 22) refletiu sobre como o silêncio e da sexualidade culminam na objetificação do corpo da mulher.

Ao contrário, na mulher há, no início, um conflito entre sua existência autônoma e seu "ser-outro"; ensinam-lhe que para agradar é preciso procurar agradar, fazer-se objeto; ela deve, portanto, renunciar à sua autonomia. Tratam-na como uma boneca viva e recusam-lhe a liberdade; fecha-se assim um círculo vicioso, pois quanto menos exercer sua liberdade para compreender, apreender e descobrir o mundo que a cerca, menos encontrará nele recursos, menos ousará afirmar-se como sujeito; se a encorajassem a isso, ela poderia manifestar a mesma exuberância viva, a mesma curiosidade, o mesmo espírito de iniciativa, a mesma ousadia que um menino.

Subjugada pela sociedade que a cerca a mulher com o papel de ser agradável e bonita como uma boneca, um objeto. O universo masculino limita a liberdade da mulher e a expressão natural de seu corpo e erotismo. Pelo material recortado do jornal, fruto do universo masculino que circunda a mulher. No universo do poema, a mulher luta pelo seu espaço, 
pois no poema ela encontra-se "sem entrada". O silêncio ecoado pela boca, infiltrando-se no perímetro do poema, o "ato 13", e toda a relação que ele estabelece com o contexto ditatorial, nos lembra que o silêncio é reforçado pela censura, pelos atos institucionais, pelo autoritarismo do Estado atingindo diretamente as lutas feministas por espaço e representatividade. Podemos pensar também a ditadura implícita na palavra "dura", dado que o silêncio imposto pela boca central impede que a palavra "dita", que compõe "ditadura", seja enunciada, pois evoca o verbo "dizer", que é justamente a ação calada pelo estado ditatorial. A partir disso, entende-se que a censura é tamanha que a palavra ditadura não pode ser posta por inteiro, pois uma parte dela ínsita a liberdade da palavra e do discurso, aqui novamente o poema assume um tom irônico de deboche da censura aplicada pelo sistema de governo autoritário.

No poema, a fragmentação das palavras recortadas do jornal permite o efeito de abertura semântica, que amplia o horizonte de sentidos das possiveis frases. Com isso em mente, tem-se o recorte da palavra "ar" que aparece duas vezes no poema: como parte de outra palavra, que não visível e como recorte individual. Algumas construções semânticas possiveis são: "ar novo" e "ar livre", ambas chamam a ideia de liberdade para o discurso. A aliteração das palavras /v/, em "novo" e "livre", e o som [r] em "livre" e "ar", prolongam ruídos fricativos que aproximam as três palavras. Pensando o cenário das lutas feministas, sugere-se que tal aproximação reinvidica a liberdade de fala e o direito de discurso e de luta, isto, liberdade para as gargantas, bocas e corpos de mulheres, que estão soterradas sob as palavras-recortes.

As palavras-recorte do poema chamam a atenção do leitor por meio da onomatopeia: "psiu", e abre um aparente espaço de fala: "vamos falar", mas essa permissão é apenas uma miragem, pois se obedecermos a leitura por meio da semelhança tipográfica temos outra construção: "vamos falar de dinheiro?". Esbarra-se aqui com a objetificação sexual da mulher: o corpo-objeto que pode ser negociado e comprado no universo masculino capitalista. Segundo Beauvoir (1980), e esse trabalho concorda com a sua colocação, a objetificação do corpo da mulher é naturalizada no comportamento social, na educação dada de forma diferente entre meninos e meninos, sobretudo com relação a liberdade sobre o próprio corpo e sexualidade, enquanto o homem é incentivado a explorá-los ao seu máximo, as mulheres são acostumadas a tratar esses como tabus. As mulheres que exploram sua sexualidade livremente são, como coloca Perrot (2003), consideradas prostitutas. Nesse sentindo, quando a boca 
sensual de Psiu (1966) é questionada a falar sobre dinheiro, lê-se a maneira pejorativa pela qual a sociedade entende a sensualidade das mulheres, como algo que pode ser negociada. No poema, o recorte da frase favorece essa perspectiva crítica, por indicar uma suposta liberdade que é revertida de maneira debochada, indicando que, no universo masculino, as mulheres são silenciadas dentro do seu próprio lugar de fala e, em geral, por meio da submissão de seus corpos ao poder de compra do dinheiro.

Nesse cenário, a liberdade é uma miragem, porque os valores e a educação que a sociedade perpetuados pela sociedade não permitem a liberdade plena. Para desenvolver esse raciocínio recorre-se ao texto Que é liberdade? (1992), de Hannah Arendt. Em seu texto, Arendt (1992) chama a atenção para o caráter abstrato e sublimativo da liberdade, visto que ao mesmo tempo que ela parece tão sólida em nossas mãos, ela nos escapa pelos vãos dos dedos. Para Arendt (1992, p. 195):

[...] a liberdade não possui realidade concreta. Sem um âmbito público politicamente assegurado, falta à liberdade o espaço concreto onde aparecer. Ela pode, certamente, habitar ainda nos corações dos homens como desejo, vontade, esperança ou anelo, mas o coração humano, como todos o sabemos, é um lugar muito sombrio, e qualquer coisa que vá para sua obscuridade não pode ser chamada adequadamente de um fato demonstrável.

Depreende-se que Arendt (1992) entende a liberdade como algo que existe entre a vontade (ou que se quer), a possibilidade de realização dessa vontade (o que se pode) e a ação para realizar a vontade. Pode parecer trivial, porém querer não é poder, existe uma lacuna entre querer e poder, que pode ser preenchida por elementos pré-determinados sócio politicamente. A sociedade, seus valores e a forma como educa suas crianças, formam os sujeitos, podando as suas vontades por meio das condições sociais impostas economica e politicamente, e limitando o poder dos sujeitos sociais. Nesse sentido, Arendt (1992, p. 210) discute a real possibilidade de realização da liberdade plena em sociedades que condicionam exteriormente comportamentos e visões de mundo, para ela "é como se o eu-quero imediatamente paralisasse o eu-posso; como se, no momento em que os homens quisessem a liberdade, eles perdessem a capacidade de ser livres" (grifos da autora). Ainda de acordo com Arendt (1992, p. 208): 


\begin{abstract}
A necessidade que me impede de fazer o que sei e quero pode surgir do mundo, ou de meu próprio corpo, ou de uma insuficiência de talentos, dons e qualidades de que o homem é dotado por nascimento e sobre os quais ele tem tanto poder quanto sobre as demais circunstâncias; todos esses fatores, sem exclusão dos psicológicos, condicionam exteriormente o indivíduo no que diz respeito ao quero e ao sei, isto é, ao próprio ego; o poder que faz face a essas circunstâncias, que liberta, por assim dizer, o querer e o conhecer de sua sujeição à necessidade, é o posso. Somente quando o quero e o posso coincidem a liberdade se consuma.
\end{abstract}

Frente ao poder do homem que circunda o mundo da mulher entende-se a liberdade como uma miragem, pois se é livre na medida que se é capaz de transcender as convenções, isto é, no momento que ultrapassa aquilo que é perpetuado pela sociedade. Nesse ponto, a atenção retorna ao poema Psiu (1966) e ao recorte "Saber Viver, Saber Ser Preso, Saber Ser Solto”, frase do ex-governador de Pernambuco Miguel Arraes, eleito por voto democrático em 1962, exilado pelo regime militar em 1964 e, novamente, eleito governador por voto democrático por mais dois mandatos posteriores à ditadura. A frase de Miguel Arraes representa a resistência de muitas lutas silenciadas pela censura do Estado, que ganham força no sistema democrático posterior à ditadura. Aqui sinalizamos, sobretudo, as discussões que circundam as lutas feministas, entre elas aquelas sobre a liberdade e representatividade das mulheres. Retomando a frase de Miguel Arraes, é preciso "saber ser solto", saber ser livre, saber o que reivindicar quando há espaço para a fala.

A liberdade, contudo, é apenas uma miragem, principalmente se considerarmos o espaço social tal como dado no poema, capaz de silenciar espaços de fala. Em um contexto de ditadura, no qual as ações de silenciamento são mais assertivas, é preciso lutar para abrir algum espaço de fala. Retomando os recortes do poema Psiu (1966), identifica-se as palavras "paz" e "revolução", que sugerem atitudes de superação da repressão imposta pelo regime político. Esses recortes podem ser associados semanticamente com o recorte da palavra "amanhã", assim podemos ler "amanhã revolução" e "paz amanhã". Essas construções podem ser entendidas como um chamado para a luta, para a revolução que precisa ser feita em todas as camadas sociais. Isso porque, é apenas por meio da revolução, que o futuro, também invocado pela palavra "amanhã", poderá ser de paz. Além disso, ao colocar a "revolução" e a "paz" no plano do amanhã, o poema apresenta uma consciência do cenário político em que nasce, dado que, em 1965-1966, a repressão imposta pela 
ditadura ainda estava em ascensão e as lutas para superação desse cenário ainda viriam a acontecer.

A revolução e a resistência são elementos fundamentais para a operação da desconstrução de padrões e convenções sociais que, de acordo com Arendt (1992), precisam ser transgredidas para a realização real da liberdade. No caso das mulheres e das lutas feministas, a efetividade da liberdade envolve a transgressão de convenções que são pilares do desenvolvimento social da civilização humana, pois o silenciamento faz parte da história feminina.

Há muito que as mulheres são as esquecidas, as sem-voz da História. O silêncio que as envolve é impressionante. Pesa primeiramente sobre o corpo, assimilado à função anônima e impessoal da reprodução. [...] Mas esse corpo exposto, encenado, continua opaco. Objeto do olhar e do desejo, não devem falar dele. O pudor que encobre seus membros ou lhes cerra os lábios é a própria marca da feminilidade. (PERROT, 2003, p. 13).

Sedutores lábios de Psiu (1966) estão cerrados e emudecidos pela história, soterrados e silenciados pelo contexto político que os envolve por meio das palavras-recortes. No poema podemos ainda ver um dedo sobre os lábios, exigindo silêncio, impondo pudor à boca sensual, pois dado que a etnica parte exposta, preciso que ela vele sua sensualidade, cale a sua fala e exista apenas para ser bonita, objeto de decoração. O silenciamento histórico da voz e do corpo das mulheres atrasaram algumas conquistas importantes para o desenvolvimento humano, isso porque é apenas com um melhor conhecimento dos corpos que se efetuam processos como "o recuo da mortalidade infantil e materna e, com isso, o aumento decisivo da longevidade das mulheres", "daí a necessidade de as mulheres se apropriarem delas, de lutarem pelo conhecimento e pela autonomia de seu corpo, grande bandeira do feminismo contemporâneo" (PERROT, 2003, p. 23).

Nessa perspectiva, Psiu (1966) é um poema que, em meio ascensão de regime ditatorial de 1966, lembrou da importância das lutas silenciadas pelo contexto de censura e repressão. Entre as lutas, a presente análise destacou as de caráter feministas, que trazem para a discussão temas como: a objetificação e o silenciamento dos corpos das mulheres, assuntos que precisam ser repensados numa sociedade que ainda é incapaz de enxergar a igual contribuição de homens e mulheres para a construção da civilização. $\mathrm{O}$ feminismo contemporâneo busca 
desconstruir as convenções socas que ainda insistem em refrear as mulheres, permitindo, assim que elas encontrem um espaço de liberdade possível para suas vozes e corpos.

\section{Considerações Finais}

Em um cenário contemporâneo de ascensão de políticas fascistas em nível mundial, recortar sincronicamente o poema Psiu (1966) e trazêlo para a discussão, principalmente sobre a ótica da análise política das lutas feministas, tem a intenção de despertar a atenção para as ações de silenciamento que sorrateiramente adentram os ambientes de resistência. Nesse sentido, o poema mantem atentos ao cenário de silenciamento iminente, lembrando que no horizonte do amanhã existe uma liberdade possível, que será alcançada pela luta e pelas ações de transgressão das convenções no presente. Retomar Psiu (1966) no contexto contemporâneo é rememorar a história das lutas contra a repressão ditatorial. Para as mulheres, ele pode ser um grito de alerta: a despeito das fortes investidas fascistas, as mulheres e seus movimentos de resistência feministas não serão mais calados.

\section{Referências}

AGUILAR, Gonzalo. Poesia Concreta Brasileira. São Paulo: Editora da Universidade de São Paulo, 2005. 404 p.

ARENDT, Hannah. Que é liberdade? In: futuro. São Paulo: Perspectiva, ed. 3, 1992. p. 188-220.

BEAUVOIR, Simone de. Infância. In: - O segundo sexo: $A$ experiência vivida. Rio de Janeiro: Editora Nova Fronteira, ed. 3, 1980. p. 9-65. (Vol. 2).

CAMPOS, Augusto de. Greve. In: . Greve. 1964. Disponível em: <http://www.augustodecampos.com.br/greve.html>

olho por olho. In: . Popcretos. 1964. Disponível em: $\overline{<\mathrm{http}: / / w w w . a u g u s t o d e c a m p o s . c o m}$.br/popcretos.html >

Psiu. In: Popcretos. 1966. <http://www.augustodecampos.com.br/popcretos.html> 
CAMPOS, Augusto de. PIGNATARI, Décio CAMPOS, Haroldo de. (1958) Plano-piloto para poesia concreta. In: . Teoria da poesia concreta. São Paulo: Livraria Duas Cidades, 2 ed, 1975. p. 156-158.

CAMPOS, Haroldo de. Olho por olho a olho nu. In: CAMPOS, Augusto de. PIGNATARI, Décio CAMPOS, Haroldo de. Teoria da poesia concreta. São Paulo: Livraria Duas Cidades, 2 ed, 1975. p. 46-48.

CORREA, Thiago Moreira. A metalinguagem na poesia de Augusto de Campos. 2012. Dissertação (Mestrado em Semiótica e Linguística Geral) - Faculdade de Filosofia, Letras e Ciências Humanas, Universidade de São Paulo, São Paulo.

COSTA, Ana Alice Alcântara. O movimento feminista no Brasil: dinâmica de uma intervenção política. In: PISCITELLI, Adriana. MELO, Hildete Pereira de. PUGA, Vera Lucia (Org.). Olhares feministas. Brasília: Ministério da Educação: UNESCO, 2009. p. 51-82.

COSTA, Daniel Rangel. A dimensão plástica dos poemas visuais de Augusto de Campos. 2019. Dissertação (Mestrado em Poéticas Visuais) Escola de Comunicação e Artes, Universidade de São Paulo, São Paulo.

JACKSON, Kenneth David. Augusto de Campos e o Trompe-L'oeil da poesia concreta. In: SÜSSEKIND, Flora. GUIMARÃES, Júlio Castañon. (Org). Sobre Augusto de Campos. Rio de Janeiro: 7Letras, 2004. p. 11-35.

PERROT, Michelle. Os silêncios do corpo da mulher. In: MATOS, Maria Izilda. SOIHET, Rachel. (Org.). O corpo feminino em debate. São Paulo: Editora UNESP, 2003. p. 13-27. 


\section{The feminine mouth in the poem Psiu by Augusto de Campos}

ABSTRACT: Concrete poetry went through a considerable period of political activism, which we can identify as attending phase (1960 - 1966). In the present project, we will focus on the analysis of Psiu (1966), a flagship poem by Augusto de Campos, which calls our attention for its heavy political tone and we propose to interpret it through the perspective of feminist resistance. This perspective is suggested by the poem itself, which presents a feminine mouth asking for silence at the center of the circle that forms it. In our reading, this silence can be related to Brazilian dictatorship repression, but it can also be the silencing of feminist resistance through the dictatorship, or even the historical silencing imposed on women as a political class.

KEYWORDS: concrete poetry; silencing; feminine body; liberty; feminism.

Monalisa Medrado BOMFIM

Mestranda em Estudos de Literatura com apoio da Coordenação de Aperfeiçoamento de Pessoal de Nível Superior (CAPES), Departamento de Letras, Universidade Federal de São Carlos (UFSCar), São Carlos, SP, Brasil. ORCID: https://orcid.org/oOoO-OOO2-1892-6085?lang=pt. E-mail:monabomfim@gmail.com.

Recebido em: 02/12/2019

Aprovado em: 25/o1/2021 